\title{
Interagindo, ouvindo o silêncio e refletindo sobre o papel do formador em chat com professores de matemática
}

\section{Interacting, listening to silence and reflecting about the role of a trainer in a chat with mathematics teachers}

\author{
Marcelo Almeida Bairral ${ }^{1}$
}

\begin{abstract}
RESUMO
Neste artigo analiso interações em um chat com professores de matemática. O foco da análise está nas funções do formador para interagir nesse tipo de bate-papo. É feito um estudo de caso e o chat é considerado a unidade de análise. A aprendizagem é entendida como formas imersivas de interação e de participação no ambiente virtual constituído. A investigação ressalta a importância da dimensão discursiva na constituição das funções do formador. Funções essas que podem ser: criatividade para elaborar atividades; iniciativa para motivar constantemente os indivíduos; solicitação de exemplos, posicionamentos, reflexões coletivas, análises e contrastes; ratificação e relativização de posicionamentos e descobertas; solicitação de informações da prática e promoção de processos autorreflexivos.

Palavras-chave: ambientes virtuais de aprendizagem; chat; funções do formador; geometria.
\end{abstract}

\begin{abstract}
In this paper I analyze interactions within a chat with mathematics teachers. The analysis was focused on the roles of the trainer to interact in this kind of environment. A case study is done and the chat is considered the unit of analysis. Learning is understood as an immersive way of interac-

1 Professor da Universidade Federal Rural do Rio de Janeiro - UFRRJ/ Programa de Pós-Graduação em Educação, Contextos Contemporâneos e Demandas Populares, Brasil. E-mail:
\end{abstract} mbairral@ufrrj.br 
tion and participation in the constituted virtual environment. The research underscores the importance of the discursive dimension on the constitution of the trainer functions. These functions can be: creativity to elaborate activities; initiative to motivate continuously the individuals; asking for examples, engagements and collective reflections, analyses and contrasts; ratification and relativity of ideas and discoveries; asking for information from practice and promoting self-reflective processes.

Keywords: learning virtual environment; chat; trainer roles; geometry.

\section{Introdução}

As ferramentas comunicativas da Internet oportunizam, mediante a escrita e outras formas de expressão do discurso, situações variadas de interação que estão cada vez mais frequentes no cotidiano dos indivíduos e em seus processos de formação. Nesse contexto, um dos objetivos das pesquisas tem sido analisar a constituição e o estudo de comunidades onde interlocutores (alunos, professores, pesquisadores, tutores) possam aprender e desenvolver-se individual e coletivamente. Todavia, em educação matemática, ainda são escassos os estudos que analisam as funções de profissionais para mediar processos interativos de modo a garantir um debate reflexivo e consubstanciado ao longo do tempo.

Em investigações anteriores analisei interações em ambientes virtuais focando mais o aprendizado dos 'aprendentes'. Naquela época era providencial mostrar para a comunidade acadêmica que era possível interagir e aprender naquele tipo de cenário. No entanto, em implementações mais recentes realizadas no grupo de pesquisa que coordeno, o Grupo de Estudos e Pesquisas das Tecnologias da Informação e Comunicação em Educação Matemática (Gepeticem) ${ }^{2}$, tenho visto a importância do formador na manutenção e continuidade do debate. Essa importância foi observada no que tange às suas habilidades comunicativas para efetivar um processo comunicativo que, dentre outras atitudes, promova a motivação e o aprofundamento da reflexão em um processo interativo mais duradouro.

Neste artigo ${ }^{3}$ apresentarei a conceituação que tenho adotado sobre ambien-

$2<$ www.gepeticem.ufrrj.br>.

3 Neste artigo exemplifico aspectos analíticos anunciados no texto suporte da palestra proferida no X Encontro Nacional de Educação Matemática - ENEM (Salvador, julho de 2010). A pesquisa foi financiada pelo Programa de Auxílio à Pesquisa (APQ) da Fundação Carlos Chagas Filho de Amparo à Pesquisa do Estado do Rio de Janeiro (Faperj) e agradeço ao licenciado Cristiano da Conceição Barreto (bolsista de Iniciação Científica - IC/Faperj, 2008/2009) pela colaboração na investigação. 
tes virtuais de aprendizagem (AVA) e, considerando um chat como um AVA, ressaltarei funções do formador na mediação com professores de matemática interagindo sobre o conceito de trapézio. Além da criatividade para elaborar atividades e da iniciativa para motivar constantemente os indivíduos, o formador pode solicitar exemplos, posicionamentos e reflexões coletivas; solicitar análises e contrastes; ratificar e relativizar posicionamentos e descobertas; solicitar informações da prática e promover processos autorreflexivos, dentre outros. O estudo também sublinha a importância da dimensão discursiva na constituição das funções do formador.

\section{Interação e aprendizagem em ambientes virtuais}

Um AVA possui os seguintes componentes: a comunidade constituída e sua intencionalidade, as normas, o propósito educativo, as tarefas de formação, os diferentes espaços comunicativos variados e os artefatos mediadores. Os artefatos podem ser ferramentas físicas ou elementos socioculturais.

A dinâmica interativa em um AVA tende a transcorrer em função das demandas sociocomunicativas dos seus participantes. Os indivíduos não são sujeitos meramente envolvidos no processo. Eles estão imersos no processo, ou melhor, eles pertencem e participam do desenvolvimento sociocomunicativo das interações. Imersão envolve um processo comportamental de autoria, de impregnação e de cumplicidade diferenciados. Imersão ${ }^{4}$ envolve fluidez, elasticidade, profundidade na forma de intervenção. Os sujeitos decidem o que discutir a partir de uma proposição prévia ou de seu desdobramento. Por outro lado, envolvimento contemplaria uma participação pontual, momentânea. Quando estou imerso em um ambiente virtual, minha sensação de pertencimento é diferenciada ${ }^{5}$. Os processos de imersão e de autoria remetem-nos, por exemplo, a um olhar da tecnologia influenciando e sendo interferida pela dimensão humana e, consequentemente, redimensiona nossa relação com os significados que produzimos.

Nos AVA que pratico, a aprendizagem é analisada pelas diferentes formas de

4 O conceito de imersão que utilizo está inspirado em Rosa (2008).

5 Por exemplo, convido o leitor que participa de comunidades como o Orkut ou o Facebook a pensar em seu comportamento e sensação quando entra nesse tipo de cenário. Ou, aquele que assistiu ao filme Procurando Nemo que relembre suas impressões e emoções. Ou, ainda, o leitor que tem a prática de acessar e navegar pelo Google Earth. A sensação é a mesma daquela quando consultamos um mapa ou movemos um globo terrestre com as mãos? Para mim, não. Essa sensação aproxima-se ao que denomino imersão. 
participação e não apenas pelos modelos particulares de aprendizagem. O processo, multidirecional, de publicização de ideias e de participação, está embebido de reflexões provenientes de diferentes contextos ${ }^{6}$ da prática dos envolvidos. Além do mais, ao possuir espaços comunicativos variados (e-mail, chat, fórum etc.), cada um assume uma dimensão discursiva própria no aprendizado. Essas singularidades irão compor o mapeamento sociocomunicativo da aprendizagem e deverão ser levadas em consideração na análise do processo formativo (BAIRRAL, 2007).

Dessa forma, a imersão (intencionalidade+pertencimento+participação) promoverá, por exemplo, um transitar entre o contexto constituído (a comunidade virtual particular) e os outros cenários de aprendizagem que também auxiliarão na produção dos significados dos interlocutores. Esses cenários são os diferentes contextos que os participantes podem integrar em suas reflexões. Por exemplo, ainda que uma determinada tarefa do AVA preconize uma série específica, "a ação de caminhar" pela tarefa trará mais sentido à medida que o seu autor faça articulações contextuais próprias. Com as perspectivas anteriores, temos utilizado a metáfora do amplificador (aumentar um sinal pequeno) e a do fotógrafo (reunir indivíduos e capturar momentos e contextos) para estudar os processos de ensino e de aprendizagem mediados por AVA.

Os AVA que constituímos são construídos com propósitos muito particulares. Esses objetivos só podem ser efetivados na comunidade de discurso constituída. A tarefa em um AVA possui a função de ser disparadora de interlocuções e de emergência e desenvolvimento de ideias. Uma tarefa, ou uma reflexão crítica de parte da mesma, constituirá a atividade formativa. Essa atividade é a que nos interessa e que analisamos. Não apenas a feitura da tarefa. A tarefa deve ser pensada em função do público a que se destina e seus objetivos não podem ficar restritos apenas à dimensão técnica e estética da tecnologia. Considerando, então, que será a necessidade do interlocutor e sua participação na comunidade que promoverá o seu aprendizado, o foco da interação passa a estar centrado na demanda do sujeito.

Seja qual for o uso de um AVA, a análise deve ser diferenciada de acordo com a sua utilização, pois a intencionalidade, o propósito e a sua dimensão discursiva, por exemplo, serão diferentes. Se forem distintas, as formas de participação também o serão. Dessa forma, os meios de obter e analisar dados serão, da mesma forma, distintos e variados. Tenho utilizado a metáfora do amplificador (aumentar um sinal pequeno) e a do fotógrafo (reunir indivíduos e capturar momentos e contextos) para entender o processo ensino-aprendizagem mediado por AVA (BAIRRAL, 2009b).

Considero interação qualquer intercâmbio comunicativo estabelecido entre

6 Contextos (curriculares) explícitos na própria tarefa formativa ou aqueles que emergem da reflexão com a tarefa e seus desdobramentos. 
os atuantes no ambiente virtual formativo, seja a partir da dinâmica de trabalho proposta nas tarefas de formação, seja de outro interesse do interlocutor. Em cada interação é possível identificar informações variadas. Elas estão relacionadas semântica e hipertextualmente com o conteúdo de alguma outra intervenção a que faz referência (implícita ou explícita) ou a algum outro contexto. No processo de capturar essas relações, o pesquisador poderá obter uma variedade de informação para inferir sobre a aprendizagem do participante.

$\mathrm{Na}$ análise, o que fazemos é construir um mapeamento sociointerativo e elucidamos aspectos emergentes na construção do conhecimento. Sendo assim, a prática que desenvolvo está centrada na análise de interações do que realmente faz, reflete e socializa o interlocutor. Não busco o que o interlocutor não faz ou não sabe, mas o que explicita no e com o coletivo constituído. Evidentemente que nesse caminhar vamos conhecendo as dificuldades conceituais dos interlocutores e procuramos saná-las. Estou denominando este caminhar de "reflexões a partir de interações positivas", ou seja, as que publiciza o interlocutor. Todas as interações postadas em um AVA são positivas, pois as mesmas podem trazer em seu bojo elementos formativos variados. No entanto, tenho visto que intervenções de cunho meramente informativo não geram uma cadeia argumentativa sustentável ao longo do tempo (BAIRRAL, 2009a).

A construção do conhecimento em ambientes virtuais é realizada hipertextualmente. Nesses ambientes, passamos a ter uma produção da escrita diferente: a hipertextual. O hipertexto é visto como uma tecnologia que rompe com a linearidade. Uma das formas de explicitar e desenvolver o pensamento é mediante a escrita. Com a escrita podemos revisar, em diferentes tempos, nosso desenvolvimento cognitivo em determinada atividade.

\section{Os chat como um tipo de TIC e de AVA}

Tenho conceituado as tecnologias da informação e comunicação (TICs) como um tipo de tecnologia que possui quatro características essenciais: conectividade, integração de mídias, dinâmica de trabalho com construção hipertextual, e interatividade. Nessa perspectiva, um chat é uma TIC. Sendo um chat, também, um ambiente virtual de aprendizagem, ele tem um propósito educativo, possui normas, constitui um grupo que, mediante artefatos mediadores variados, buscará a construção do conhecimento.

Em um projeto de formação continuada com professores analisei (BAIRRAL, 2004) interações em bate-papos e apresentei uma estratégia constituída 
de quatro fases (planejamento e delimitação de objetivos, análise da discussão no coletivo, análise personalizada, contraste) para analisar um chat. No que se refere à análise coletiva, identifiquei diferentes momentos: recepção e identificação pessoal, inspiração, controle e problematização, aprofundamento na tarefa proposta com base na experiência profissional, aprofundamento orientado em referenciais teóricos com exemplificação de elementos da prática e, por último, intervenção com caráter e interesse geral. Em um estudo posterior, desenvolvido com colaboradores (BAIRRAL; POWELL; SANTOS, 2007), sublinhei que, ao contrário dos docentes, que normalmente procuram discutir e aprofundar-com maior demanda de tempo - sua compreensão conceitual na atividade, os alunos tendem a ser mais imediatos. Os formadores (professores e pesquisadores) foram importantes na revisão e discussão dos procedimentos próprios e dos colegas.

O chat é um espaço que integra discursos de outros espaços como o fórum e o e-mail, por exemplo. Não quero dizer que isso o torna mais potencial que os demais, mas que a análise isolada dos bate-papos pode não ser suficiente. Quando necessário, a análise pode ser enriquecida com informação proveniente de outros espaços comunicativos do ambiente. Quando analiso diferentes chats, por exemplo, opto por simbolizar a conjunção desses bate-papos como (chat $1+2+\ldots+$ n) e não como (chat $1,2, \ldots, n$ ). Para mim, esse tipo de simbolização remeteria a um entendimento fragmentado do processo interativo, ou seja, batepapos sem conexões, isolados cognitiva e discursivamente.

Sendo o chat um espaço discursivo e suporte cognitivo para um grupo específico, ele não apenas amplia as habilidades individuais dos indivíduos como, também, torna possível a constituição de diferentes grupos $\operatorname{cognitivos}^{7} \mathrm{e}$, consequentemente, de formas distintas de interação (STAHL, 2006). Acrescenta esse autor, que o uso dessas ferramentas acontece através das interações entre os sujeitos e não individualmente. Dessa forma, a aprendizagem não pode ser vista como um produto em si mesmo, mas uma conjunção de aspectos (exemplos, conceitos, concepções, sugestões etc.) que vão se desenvolvendo no coletivo.

O processo analítico deve estar baseado em duas dimensões da interação: a cognitiva (atitudes e habilidades, crenças e conhecimento prévio, processos de raciocínio e formas de representação, motivação, emoção) e a social (colaboração, formas de compartilhamento, relações pessoal-profissionais diversas e os diferentes contextos envolvidos). Cabe, portanto, sublinhar que interação, aprendizagem e avaliação devem ser vistos como domínios intimamente relacionados. Embora existam momentos autorreflexivos, as interações envolvem

7 Segundo Stahl (2006), grupo cognitivo constitui uma forma de cognição distribuída que envolve raciocínios avançados como resolução de problemas e que são visíveis na comunidade discursiva. 
coletividades. Vejamos, então, como busco contemplar esse processo de análise.

\section{Os ambientes virtuais que pratico, participo e aprendo em educa- ção matemática}

Em minha apresentação no II Seminário Brasileiro de Psicologia da Educação Matemática ${ }^{8}$, ilustrei estratégias de análise que estão sendo implementadas em três ambientes virtuais em que estou envolvido: AVA do Gepeticem (BAIRRAL, 2007), portfólios eletrônicos (COSTA, 2009) e o VMT-Chat ${ }^{9}$. A seguir, ilustro o caminho para analisar a atividade constituída em cada ambiente virtual exemplificado em minha intervenção.

\begin{tabular}{|c|c|c|c|c|}
\hline Ambiente & $\begin{array}{c}\text { Estratégias } \\
\text { metodológicas }\end{array}$ & Foco da análise & $\begin{array}{c}\text { Foco no } \\
\text { sujeito }\end{array}$ & Tipo de análise \\
\hline Gepeticem & $\begin{array}{l}\text {-Espaços } \\
\text { comunicativos } \\
\text { (e-mail, chat, fórum) } \\
\text {-Arquivos do Word / } \\
\text { resposta de tarefas } \\
\text {-Questionário online } \\
\text {-Diários do } \\
\text { pesquisador } \\
\text {-Log-file }\end{array}$ & $\begin{array}{l}\text {-Desenvolvimento do } \\
\text { conhecimento a partir } \\
\text { do "fazer" de uma tarefa } \\
\text { a partir de uma decisão } \\
\text { individual }\end{array}$ & \multirow[t]{2}{*}{$\begin{array}{l}\text { Indivíduo } \\
\text { no/com } \\
\text { grupo }\end{array}$} & \multirow[t]{3}{*}{$\begin{array}{l}\text { Estudos de caso } \\
\text { (descritivo e } \\
\text { interpretativo) }\end{array}$} \\
\hline VMT-Chat & $\begin{array}{l}\text {-Transcrição } \\
\text {-Player } \\
\text {-Observação } \\
\text {-Questionário }\end{array}$ & $\begin{array}{l}\text {-Emergência e } \\
\text { desenvolvimento de } \\
\text { aspectos (heurísticas) no/ } \\
\text { do conhecimento em uma } \\
\text { dimensão colaborativa } \\
\end{array}$ & & \\
\hline$e$-Portfólio & $\begin{array}{l}\text {-Processo de } \\
\text { construção } \\
\text {-Observação } \\
\text {-Entrevista }\end{array}$ & $\begin{array}{l}\text {-Emergência e } \\
\text { desenvolvimento } \\
\text { de aspectos no/do } \\
\text { conhecimento no processo } \\
\text { de construção do portfólio } \\
\text { (individualizada) }\end{array}$ & $\begin{array}{l}\text { Indivíduo } \\
\text { para um } \\
\text { grupo / } \\
\text { indivíduo }\end{array}$ & \\
\hline
\end{tabular}

QUADRO 1 - AMBIENTES E ESTRATÉGIAS PARA OBTENÇÃO DE INFORMAÇÃO E ANÁLISE

8 Ocorrido na UFPR em março de 2010.

9 Com Arthur B. Powell (Rutgers University) e Gerry Stahl (Drexel University) e suas respectivas equipes de investigação. Para saber mais sobre o tipo de análise realizada, veja os anais do II SIPEMAT (Recife, 2008) e do IV SIPEM (Brasília, 2009). 
Enquanto no AVA há uma coletividade constituída, no portfólio eletrônico a constituição será feita a partir dos interesses e visitas de cada interlocutor ao espaço virtual. Dessa forma, as formas de imersão e os processos de autoria passam a ser diferenciados. Daí a importância do formador saber dessa diferenciação para promover processos imersivos e autorais observando a coletividade e a individualidade. Em um AVA, embora a construção seja uma função do pesquisador ou do formador, o aluno pode reconstruir as tarefas de formação, por exemplo, a partir de suas formas de entendimento das mesmas (BAIRRAL, 2007). A sensibilidade para considerar as formas diferentes de interpretar e reconstruir uma tarefa é uma importante função do formador. Vejamos, então, um exemplo de análise realizada em um chat.

\section{A proposta discutida no chat analisado}

Conforme estudo anterior (BAIRRAL, 2004), o planejamento de um chat deve estar orientado para uma discussão específica, ou seja, deve começar a partir de uma situação concreta (atividade, discussão de um artigo etc.). É importante que sejam sugeridas mais de uma proposta para discussão. Dependendo do propósito do bate-papo e do perfil dos cursistas, o formador pode variar o tempo de antecedência para o envio do planejamento. No entanto, esse tempo não pode ter um grande intervalo, pois é relevante garantir uma reflexão mais instantânea e imersiva no chat. Sendo a proposta enviada com muita antecedência, a curiosidade e o fator surpresa perdem sua função.

A duração inicial estipulada para cada chat é variável. Em nosso caso, ela tem variado entre 40 e 120 minutos. Como no ambiente do Gepeticem há impossibilidade de inserção de imagens ou de desenhos, o que fazemos é pensar em propostas que evitem justificativas com esse tipo de representação.

As atividades de nosso planejamento assumem duas perspectivas: são situações de sondagem e de aprofundamento de reflexões previamente compartilhadas no AVA. Tenho visto que, sobretudo na formação continuada, esse tipo de proposição é frutífera. A proposta do chat analisado nesse artigo foi constituída de duas atividades, integrantes do conjunto de 
tarefas do curso $^{10}$, a saber:

\section{Atividade obrigatória 4 (OB4)}

Acesse três sites diferentes e veja a definição que os mesmos apresentam para trapézio. Analise, comparando, as definições que você obteve.

\begin{tabular}{|l|l|l|}
\hline Endereço do site & Definição apresentada & Seus comentários \\
\hline & & \\
\hline & & \\
\hline & & \\
\hline
\end{tabular}

\section{Atividade obrigatória 5 (OB5)}

A seguir você vê duas organizações esquemáticas ${ }^{11}$ sobre quadriláteros apresentadas por alunos do $9 .^{\circ}$ ano. Identifique a definição de quadrilátero implícita em cada esquema. A partir dos seus conhecimentos e das repostas obtidas na atividade 4 analise os esquemas.

Os professores tiveram um tempo para realizar cada atividade anterior e o propósito do chat era refletir sobre seus resultados e aprofundar a análise sobre suas descobertas.

10 Trata-se de um curso (presencial) de capacitação realizado com professores de matemática. O ambiente virtual do curso foi opcional. As atividades disponíveis focaram a análise de conceitos geométricos.

11 O esquema 2 foi retirado de Veloso (1998, p. 381). 


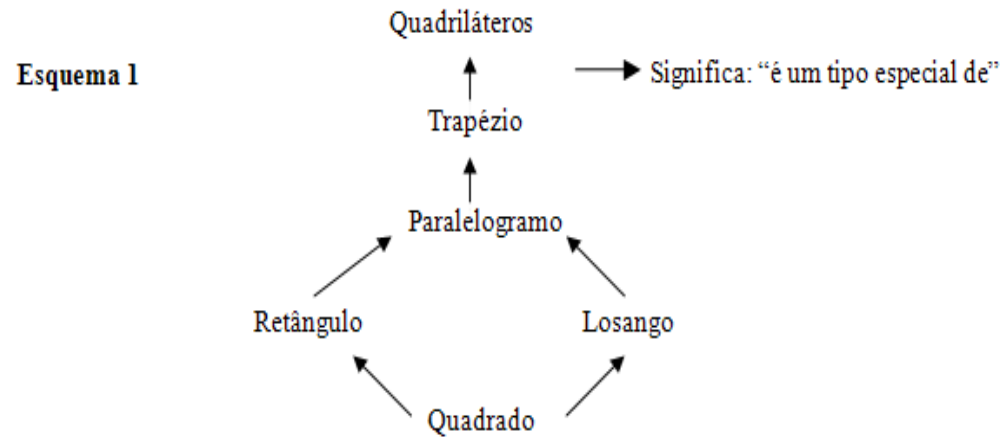

Esquema 2

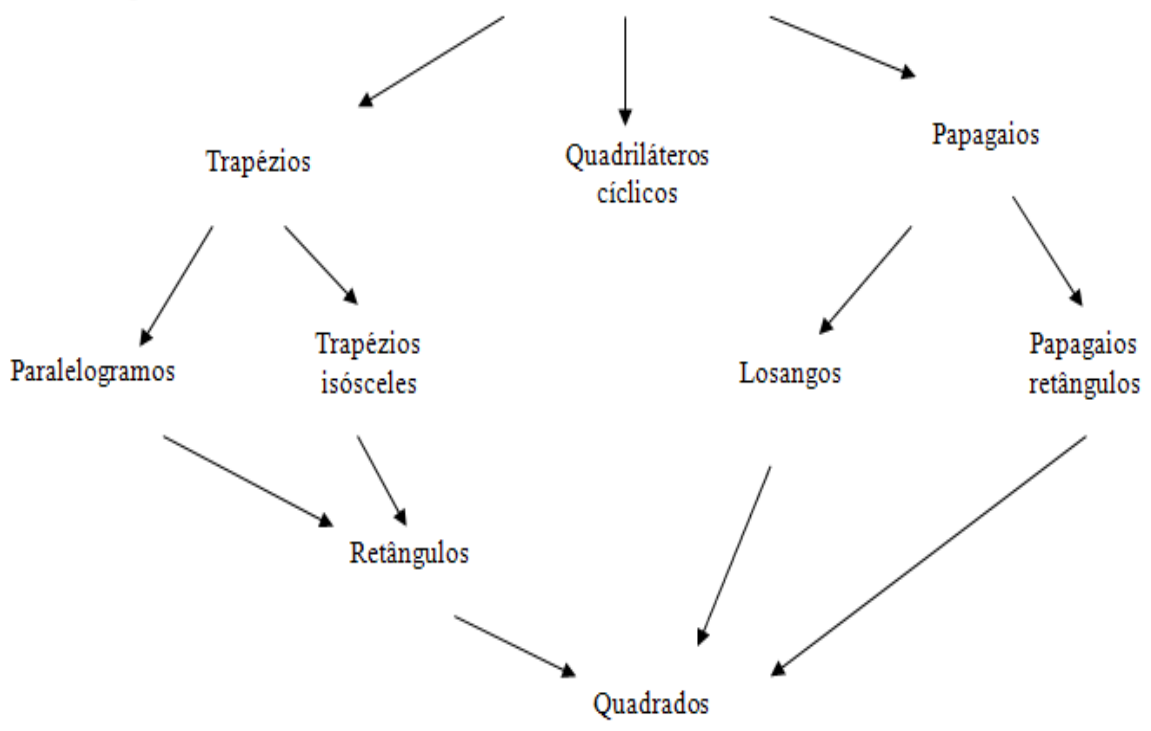




\section{O chat do Gepeticem como objeto de análise}

Em pesquisa anterior (BAIRRAL, 2004), propus quatro fases para analisar a dinâmica interativa em um chat da natureza do AVA do Gepeticem: a fase 1 (delimitação dos objetivos e planejamento), a fase 2 (análise da discussão no coletivo profissional), a fase 3 (análise personalizada) e a fase 4 (contraste e meta-análise de todo o processo formativo).

No presente estudo adotei as três primeiras fases. No âmbito da fase dois foram utilizados os seguintes procedimentos: transcrição do chat (arquivo fornecido pela própria plataforma); numeração (em linhas) das interações; retirada de linhas com ideia não focada na análise ${ }^{12}$; releitura das interações e organização em momentos. Não realizei nenhuma análise personalizada, pois o foco esteve na elucidação de funções do formador no coletivo constituído.

Apresento alguns fragmentos do debate no chat obrigatório. As palavras ou expressões negritadas são marcadores que exemplificam os elementos considerados na análise semântica do discurso. O chat teve um total de 81 (oitenta e uma) linhas. Juntamente com o formador participaram cinco professores. Cada profissional foi identificado como professor $(1,2, \ldots, 5)$. O bate-papo durou 1 h $58 \mathrm{~min}$.

\section{Resultados}

Foram identificados três grandes momentos no chat: recepção e esclarecimento da proposta (L1-L29), aprofundamento e análise da atividade (L2769), chamada para encerramento e despedida (L70-81). Os momentos não são estanques, disjuntos. Eles estão imbricados. Passado o momento de recepção (L1-18), o fragmento a seguir ilustra o formador reapresentando a proposta do chat. Nas linhas 27 e 29, ele considera as ideias iniciais do professor2 e provoca uma implicação do coletivo sobre o tipo de definição encontrada. 


\begin{tabular}{|c|c|c|}
\hline Linha(s) & Transcrição & Formador \\
\hline \begin{tabular}{|l|} 
L19 \\
\end{tabular} & $\begin{array}{l}\text { Formador }(17 / 09 / 2009 \text { - } 11 \mathrm{~h} 55 \mathrm{~min}: 42) \text { : o propósito do } \\
\text { nosso chat hoje é discutir um pouco sobre o que nosso aluno } \\
\text { aprende quando faz as atividades OB } 4 \text { e OB } 5\end{array}$ & $\begin{array}{l}\text { Apresentação do } \\
\text { propósito do chat }\end{array}$ \\
\hline L23 & $\begin{array}{l}\text { Professor2 }(17 / 09 / 2009-12 \mathrm{~h} 01 \mathrm{~min}: 26) \text { : atividade OB4: } \\
\text { fazendo a busca na internet, muitos sites apresentam o } \\
\text { assunto, de formas diferentes a ser abordado. Diferentes } \\
\text { exemplos, diferentes ferramentas... }\end{array}$ & \\
\hline L26 & $\begin{array}{l}\text { Professor2 }(17 / 09 / 2009 \text { - } 12 \mathrm{~h} 02 \mathrm{~min}: 32): \text { entretanto, deve-se } \\
\text { ter o cuidado para "aceitar" o que é apresentado, pois nem } \\
\text { sempre está descrito, ou definido de forma correta... }\end{array}$ & \\
\hline L27 & $\begin{array}{l}\text { Formador (17/09/2009 - } 12 \mathrm{~h} 03 \mathrm{~min}: 58) \text { : isso Professor2, } \\
\text { você poderia dar um exemplo do que você encontrou e que } \\
\text { não estava bem descrito? }\end{array}$ & $\begin{array}{l}\text { Considerando e } \\
\text { solicitando exemplo }\end{array}$ \\
\hline L28 & $\begin{array}{l}\text { Professor2 }(17 / 09 / 2009-12 \mathrm{~h} 04 \mathrm{~min}: 12) \text { : Por isso a } \\
\text { importância de fazer várias buscas e comparar os resultados } \\
\text { apresentados }\end{array}$ & \\
\hline L29 & $\begin{array}{l}\text { Formador }(17 / 09 / 2009 \text { - } 12 \mathrm{~h} 06 \mathrm{~min}: 58) \text { : isso, vocês } \\
\text { encontraram alguma definição diferente (interessante, } \\
\text { incompleta, errada, ...)? }\end{array}$ & $\begin{array}{l}\text { Considerando, atenção } \\
\text { ao coletivo e implicação }\end{array}$ \\
\hline
\end{tabular}

O segundo momento do bate-papo é aquele onde há um processo imersivo de aprofundamento na atividade. Sabemos que os livros didáticos de matemática comumente apresentam a definição de trapézio como quadrilátero que possui um par de lados paralelos ou, dito de outro modo, um quadrilátero com dois lados paralelos. No entanto, outra definição é possível e raramente apresentada nos livros, ou seja, a que define trapézio como um quadrilátero que possui apenas um único par de lados opostos paralelos. Sendo assim, nesse momento, transcrito a seguir, observamos o formador solicitar posicionamento e aprofundamento nas descobertas. É possível identificar que os docentes (1 e 3) estão estabelecendo relações a partir das definições emergentes. O professor3, após uma dificuldade explicitada (L33), mostra compreensão com a relação que estabelece (L40), inclusive, acrescentando a ideia de convexidade na definição que exemplifica.

\begin{tabular}{|l|l|c|}
\hline Linha(s) & \multicolumn{1}{|c|}{ Transcrição } & Formador \\
\hline L32 & $\begin{array}{l}\text { Professor1 }(17 / 09 / 2009-12 \mathrm{~h} 07 \text { min:31) : A atividade } \\
\text { OB4 permite a ele ver q um paralelogramo também é um } \\
\text { trapézio }\end{array}$ & \\
\hline L33 & $\begin{array}{l}\text { Professor3 }(17 / 09 / 2009-12 \mathrm{~h} 07 \mathrm{~min}: 44): \text { Eu tive } \\
\text { dificuldades para realizar as tarefas em questão, e não sei se } \\
\text { as realizei corretamente. }\end{array}$ & \\
\hline
\end{tabular}


conclusão

\begin{tabular}{|c|c|c|}
\hline L34 & $\begin{array}{l}\text { Professor1 }(17 / 09 / 2009-12 \mathrm{~h} 08 \mathrm{~min}: 37): \underline{\mathrm{O} \text { aluno percebe }} \\
\begin{array}{l}\text { que os quadriláteros são divididos nos trapézios e não } \\
\text { trapézios }\end{array}\end{array}$ & \\
\hline L36 & $\begin{array}{l}\text { Professor1 }(17 / 09 / 2009 \text { - } 12 \mathrm{~h} 10 \mathrm{~min}: 30): \text { Mostra para ele } \\
\text { q na definição de trapézio não há a necessidade de se ter } \\
\text { apenas dois lados paralelos }\end{array}$ & \\
\hline L37 & $\begin{array}{l}\text { Formador }(17 / 09 / 2009 \text { - } 12 \mathrm{~h} 10 \mathrm{~min}: 40) \text { : Professor1, } \\
\text { interessante! o paralelogramo também é um trapézio! o } \\
\text { que fazer para o aluno perceber isso? }\end{array}$ & $\begin{array}{l}\text { Considerando; solicitando } \\
\text { posicionamento }\end{array}$ \\
\hline L38 & $\begin{array}{l}\text { Professor1 }(17 / 09 / 2009-12 \mathrm{~h} 12 \mathrm{~min}: 46) \text { : Com essa } \\
\text { atividade mostra-se que tanto os retângulos quanto os } \\
\text { losangos são trapézios }\end{array}$ & \\
\hline L39 & $\begin{array}{l}\text { Formador }(17 / 09 / 2009-12 \mathrm{~h} 14 \mathrm{~min}: 13) \text { : isso, mas o que } \\
\text { está implícito nesta descoberta? }\end{array}$ & $\begin{array}{l}\text { Confirmando; solicitando } \\
\text { aprofundamento }\end{array}$ \\
\hline L40 & $\begin{array}{l}\text { Professor3 }(17 / 09 / 2009-12 \mathrm{~h} 14 \mathrm{~min}: 55) \text { : "todo } \\
\text { quadrilátero convexo que tem dois lados paralelos". } \\
\text { Sendo assim, todo paralelogramo é trapézio, pois todo } \\
\text { paralelogramo tem dois lados paralelos. }\end{array}$ & \\
\hline
\end{tabular}

A reflexão coletiva transcorre naturalmente e com visível compreensão por parte dos interlocutores. Todavia, apesar da satisfação em perceber que os docentes mostram entendimento das definições, o formador identifica certo silêncio de alguns docentes, principalmente, os professores 2, 4 e 5. Eles aparentavam estar acompanhando e concordando com a discussão, mas o formador não tinha certeza. Sendo assim, esse faz uma pergunta sobre a presença dos professores (L41, a seguir) e eles lhe respondem que estão conectados. Esse comportamento silencioso foi curioso para o formador que percebeu que, mesmo sem postar uma ideia, os educadores estavam presentes. A resposta afirmativa (L43-46) ratifica a suposição de que os profissionais estavam silenciosamente imersos e compreendendo a discussão. O silêncio dos professores mostra a importância do formador prestar atenção nesse tipo de comportamento e não ficar antecipando o tempo de reflexão dos seus alunos. Vejamos o fragmento.

\begin{tabular}{|l|l|l|}
\hline Linha(s) & \multicolumn{1}{|c|}{ Transcrição } & \multicolumn{1}{|c|}{ Formador } \\
\hline L41 & $\begin{array}{l}\text { Formador }(17 / 09 / 2009-12 \mathrm{~h} 15 \mathrm{~min}: 28): \text { Professor3, } \\
\text { Professor5, Professor2, Professor4 estão aí? }\end{array}$ & $\begin{array}{l}\text { Atenção ao silêncio } \\
\text { (chamada online) }\end{array}$ \\
\hline L42 & $\begin{array}{l}\text { Formador }(17 / 09 / 2009-12 \mathrm{~h} 15 \mathrm{~min}: 59): \text { muito bem } \\
\text { Professor3! }\end{array}$ & Animando \\
\hline
\end{tabular}


conclusão

\begin{tabular}{|c|c|c|}
\hline L43-46 & $\begin{array}{l}\text { Professor5 }(17 / 09 / 2009-12 \mathrm{~h} 16 \mathrm{~min}: 02): \operatorname{sim} . \\
\text { Professor3 }(17 / 09 / 2009-12 \mathrm{~h} 16 \mathrm{~min}: 18): \operatorname{Sim} \\
\text { Professor2 }(17 / 09 / 2009-12 \mathrm{~h} 16 \mathrm{~min}: 24): \operatorname{sim} \\
\text { Professor4 }(17 / 09 / 2009-12 \mathrm{~h} 16 \mathrm{~min}: 32): \operatorname{sim}\end{array}$ & \\
\hline L47 & Formador $(17 / 09 / 2009$ - 12h16min:44) : que bom! & \\
\hline L48 & $\begin{array}{l}\text { Formador }(17 / 09 / 2009-12 \mathrm{~h} 20 \mathrm{~min}: 21) \text { : a definição que o } \\
\text { Professor3 apresentou para trapézio foi “todo quadrilátero } \\
\text { convexo que tem dois lados paralelos". Alguém viu outra ou } \\
\text { tem utilizado uma diferente? }\end{array}$ & $\begin{array}{l}\text { Considerando; } \\
\text { provocando análise } \\
\text { coletiva }\end{array}$ \\
\hline L49 & $\begin{array}{l}\text { Professor3 (17/09/2009 - 12h21min:46) : existem livros de } \\
\text { matemática que definem trapézio assim: "é todo quadrilátero } \\
\text { convexo que tem dois lados paralelos e dois lados não } \\
\text { paralelos". Dessa maneira nenhum paralelogramo seria } \\
\text { trapézio. }\end{array}$ & \\
\hline L51 & $\begin{array}{l}\text { Professor1 }(17 / 09 / 2009 \text { - } 12 \mathrm{~h} 23 \mathrm{~min}: 54) \text { : Redefinir } \\
\text { quadriláteros. Mostrar através de exemplos concretos q um } \\
\text { paralelogramo tem mais q dois lados paralelos. Mostrar q o } \\
\text { paralelogramo é um caso particular de trapézio. Um trapézio } \\
\text { em que os lados opostos são paralelos }\end{array}$ & \\
\hline L53 & $\begin{array}{l}\text { Professor } \mathbf{5}(17 / 09 / 2009-12 \mathrm{~h} 25 \mathrm{~min}: 12): \text { achei essa também } \\
\text { e como um quadrilátero notável, soma dos ângulos internos é } \\
\text { igual a } 360 \text {. }\end{array}$ & \\
\hline L54 & $\begin{array}{l}\text { Formador }(17 / 09 / 2009-12 \mathrm{~h} 26 \mathrm{~min}: 35) \text { : então vocês devem } \\
\text { ter percebido que há definições diferentes }\end{array}$ & $\begin{array}{l}\text { Ressaltando, } \\
\text { ratificando }\end{array}$ \\
\hline L55-56 & $\begin{array}{l}\text { Professor3 }(17 / 09 / 2009-12 \mathrm{~h} 27 \mathrm{~min}: 01): \text { com certeza } \\
\text { Professor5 }(17 / 09 / 2009-12 \mathrm{~h} 27 \mathrm{~min}: 16): \text { isso }\end{array}$ & \\
\hline L57-58 & $\begin{array}{l}\text { Formador }(17 / 09 / 2009-12 \mathrm{~h} 27 \min : 46): \text { e que dependendo } \\
\text { da definição, teremos classificações diferentes para os } \\
\text { quadriláteros } \\
\text { Formador }(17 / 09 / 2009-12 \mathrm{~h} 28 \mathrm{~min}: 15) \text { : vocês fazem este tipo } \\
\text { de discussão em aula? }\end{array}$ & $\begin{array}{l}\text { Ressaltando, } \\
\text { relativizando, } \\
\text { solicitando } \\
\text { informações da } \\
\text { prática }\end{array}$ \\
\hline
\end{tabular}

Transcorridos os minutos da reflexão silenciosa de alguns professores e estando o formador ratificando posicionamentos, solicitando informações e estimulando análise coletiva, vemos a seguir emergirem ideias com implicações de cunho didático.

\begin{tabular}{|l|l|l|}
\hline Linha(s) & \multicolumn{1}{|c|}{ Transcrição } & \multicolumn{1}{|c|}{ Formador } \\
\hline L60 & $\begin{array}{l}\text { Formador }(17 / 09 / 2009-12 \mathrm{~h} 29 \mathrm{~min}: 15) \text { : Professor5, eu não } \\
\text { conhecia a tua definição de trapézio. Interessante! }\end{array}$ & $\begin{array}{l}\text { Considerando, } \\
\text { animando }\end{array}$ \\
\hline L61 & $\begin{array}{l}\text { Formador }(17 / 09 / 2009-12 \mathrm{~h} 29 \mathrm{~min}: 39): \text { e como fazer para } \\
\text { não confundir? }\end{array}$ & $\begin{array}{l}\text { Suscitando reflexão } \\
\text { de cunho didático }\end{array}$ \\
\hline
\end{tabular}


conclusão

\begin{tabular}{|l|l|l|}
\hline L63-64 & $\begin{array}{l}\text { Professor5 (17/09/2009 - 12h31min:33) : pedindo aos alunos } \\
\text { para construírem as figuras } \\
\text { Professor3 (17/09/2009 - 12h32min:48) : Usando a } \\
\text { criatividade e utilizando de alguns materiais concretos para que } \\
\text { o aluno não fique "viajando" nas definições }\end{array}$ & \\
\hline L65 & $\begin{array}{l}\text { Formador }(17 / 09 / 2009-12 \mathrm{~h} 33 \mathrm{~min}: 23) \text { : o que vocês } \\
\text { consideram que aprenderam com as atividades? } \\
\text { Formador }(17 / 09 / 2009-12 \mathrm{~h} 33 \mathrm{~min}: 53) \text { : elas lhe trouxeram } \\
\text { alguma ideia nova, inspiração ...? }\end{array}$ & $\begin{array}{l}\text { Promovendo } \\
\text { autorreflexão sobre } \\
\text { o aprendizado e } \\
\text { implicação }\end{array}$ \\
\hline L67 & $\begin{array}{l}\text { Professor1 }(17 / 09 / 2009-12 \mathrm{~h} 34 \mathrm{~min}: 04) \text { : eu fiz esse tipo } \\
\text { de discussão com os alunos e eles de início não entenderam } \\
\text { muito até perceberem que se tratava de uma retificação de um } \\
\text { conceito que eles conheciam }\end{array}$ & \\
\hline L69 & $\begin{array}{l}\text { Professor3 (17/09/2009 - 12h38min:19) : Sim, essas atividades } \\
\text { me ensinaram que não podemos ficar inertes nos conceitos, } \\
\text { temos que buscar soluções que satisfaçam nossas expectativas } \\
\text { e as dos alunos. Temos que estar sempre nos capacitando para } \\
\text { podermos melhorar a qualidade de nossas aulas. }\end{array}$ & \\
\hline L70-71 & $\begin{array}{l}\text { Formador (17/09/2009 - 12h39min:11) : que bom! } \\
\text { Formador (17/09/2009 - 12h40min:48) : colegas. Gostei } \\
\text { bastante de ter conversado com vocês no chat. Como } \\
\text { planejado, podemos concluir. Claro que quem puder pode } \\
\text { continuar e quem chegar depois pode ver nossas ideias e fazer } \\
\text { observações, complementos etc. }\end{array}$ & Concluindo \\
\hline
\end{tabular}

Através dos fragmentos anteriores podemos perceber que o objetivo do chat foi alcançado, qual seja, o de promover reflexão e aprofundamento teórico sobre a definição de trapézio. É visível, em diferentes momentos e falas (L23, L51, L53, L67, L69), que os docentes descobriram algo de inovador a partir do proposto.

Do ponto de vista do formador, a análise suscitou as seguintes das funções: apresenta o propósito do chat (L19); considera e solicita exemplo (L27), provoca implicação (L29), solicita posicionamento (L37), provoca análise coletiva (48, 54); confirma ideia e solicita aprofundamento (L39); presta atenção ao silêncio (L41); anima (L42); ressalta, relativiza e solicita informações da prática (L5758); propicia reflexão de cunho didático (L61); promove autorreflexão sobre o aprendizado e busca implicação (L65); e finaliza o bate-papo (170-71). Essas funções podem acontecer em diferentes momentos do processo. 


\section{Encaminhamentos conclusivos}

Ainda que o foco desse estudo tenha sido no formador, concretamente, sem suas funções emergentes, é possível observar que os professores aprenderam com as interações no chat. Por exemplo, as falas transcritas nas linhas 26, 33, 36, 55, 57, 65, 69 ilustram suas descobertas e aprendizagens sobre uma outra definição de trapézio e, consequentemente, uma classificação para os quadriláteros diferente daquela comumente presente nos livros didáticos.

É importante destacar que as funções do formador têm uma dimensão discursiva, estratégica. Essa dimensão é importante para que o formador desenvolva, de acordo com o ambiente virtual que utiliza, um conjunto de habilidades para a promoção de uma reflexão reflexiva e compartilhada ao longo do tempo. A dimensão discursiva não é condição suficiente, mas necessária. Essa dimensão considera que a interação assuma diferentes facetas de acordo com o espaço comunicativo (e-mail, chat, fórum etc.) onde se efetiva. Há habilidades que são comuns, mesmo em espaços diferentes. Essas singularidades discursivas devem ser levadas em consideração.

Tenho visto práticas frequentes em ambientes virtuais que estimulam a quantidade de interação e o estudante é avaliado em função dessa quantidade de postagem. No entanto, não é o número de intervenções que implica a construção do conhecimento e, sim, a disponibilidade e a abertura dos interlocutores para aprofundar-se na discussão a partir da problemática proposta. O compromisso e a colaboração com que os docentes se envolvem no debate - quando percebem seus interesses profissionais respeitados e valorizados - são fatores que interferem significativamente na qualidade da discussão virtual e em sua continuidade.

Uma discussão em um chat, apesar de determinada temporalmente, pode ser continuada em outros espaços comunicativos do ambiente virtual de acordo com os interesses dos agentes comunicadores. Da mesma forma que uma ideia vem ao chat a partir da reflexão propiciada por uma situação prévia, essa ideia pode continuar em outro tipo de situação e espaço. Essa dinâmica hipertextual faz com que o conhecimento seja construído em uma dinâmica interativa que rompa com fronteiras de instrumentos isolados e passe a ter um espectro mais abrangente e amplificador (BAIRRAL, 2009b).

Diferentes chats $($ chat $1+2+\ldots+\mathrm{n})$ devem analisados para enriquecer a análise e o processo interativo. Como processo coletivo conjuntivo, estamos de acordo com Stahl (2006), de que a interação deixa ser acidental ou competitiva e assume um papel onde o grupo se esforça para o trabalho e o aprendizado conjunto. Um pequeno grupo de indivíduos colaborando online, sublinha Stahl (2006), pode pensar e aprender como um grupo, não como uma soma de pessoas interagindo e aprendendo individualmente.

Em cenários virtuais o formador tem que interpretar globalmente as intervenções 
e respondê-las ora de forma individual, ora coletivamente. Esse processo interpretativo necessita tempo e imersão. Ele é um exemplo característico de que os processos de formação à distância mediados pelos AVA exigem tempo de dedicação pela equipe proponente. Por isso, a construção de procedimentos analíticos é importante.

Finalmente, infelizmente, alguns estudos no campo da informática educativa ainda analisam a aprendizagem somente do ponto de vista técnico, isto é, colocando a essência na informática. Penso que a dimensão humana é a que deve prevalecer, ou seja, é a partir da aprendizagem que devemos reconfigurar aspectos técnicos de um cenário virtual.

\section{REFERÊNCIAS}

BAIRRAL, M. A. Compartilhando e construindo conhecimento matemático: análise do discurso nos chats. BOLEMA, v. 17, n. 22, p. 37-61, 2004.

. Discurso, interação e aprendizagem matemática em ambientes virtuais à distância. Rio de Janeiro: Edur, 2007.

. Learning in virtual environments: a methodology for the analysis of teacher discourse. JIEEM, v. 1, n. 1, p. 47-70, 2009a.

. Tecnologias da informação e comunicação na formação e educação matemática. Rio de Janeiro: Edur, 2009b. v. 1.

BAIRRAL, M. A.; POWELL, A. B.; SANTOS, G. T. dos. Análise de interações de estudantes do Ensino Médio em chats. Educação e Cultura Contemporânea, v. 4, n. 7, p. 113-138, 2007.

COSTA, R. C. O uso de e-Portfólios na aprendizagem de alunos do Instituto Federal de Educação, Ciências e Tecnologia do Maranhão/Campus Codó. Dissertação (Mestrado em Educação Agrícola) - Universidade Federal Rural do Rio de Janeiro/PPGEA, Seropédica, 2009.

ROSA, M. A Construção de identidades online por meio do role playing game: relações com o ensino e a aprendizagem de matemática em um curso à distância. Tese (Doutorado em Educação Matemática) - UNESP, Rio Claro, 2008.

STAHL, G. Group cognition: Computer support for building collaborative knowledge. Cambridge: MIT, 2006.

VELOSO, E. Geometria: temas actuais: materiais para professores. Lisboa: IIE, 1998. 
